\section{Moving forward with steady strokes in paralympic sports medicine}

\author{
Hilde Moseby Berge
}

We have just returned from the 5th IOC World Conference on Prevention of Illness and Injuries in Sport in Monaco. As always, it was great to meet old and new colleagues in sport and exercise medicine, listen to interesting talks, and participate in the workshops. The new sessions on Paralympic sports medicine were highlights for us.

The extra challenges of taking care of paralympic athletes are highlighted by Melbourne's Liam West et al (see page 1050) in their editorial on how to manage concussion in disability sport. In another editorial, Tweedy et al (see page 1048) discuss how enabling technology can improve the performance of paralympic athletes, to such an extent that take-off velocity of a unilateral below-knee amputee with a long jumpspecific prosthesis is higher than that of able-bodied athletes. Strikingly, the athlete with a disability has a personal best that would have won Gold at the London Olympics.

Many athletes with disability are born with, or suffer from, serious chronic diseases. One is inflammatory rheumatic disease, and traditional dogma was that exercise would exacerbate disease activity-both athletic activity and health promoting exercise were discouraged. Good that Sveaas et al (see page 1065) showed in a systematic review that both cardiorespiratory and strength exercises limit disease activity, and that the athlete can take advantage of the numerous health effects of increased physical fitness, such as better cardiovascular health. This study is not the only one to reveal that

Norwegian School of Sport Sciences, Oslo Sports Trauma Research Center, Oslo, Norway

Correspondence to Dr Hilde Moseby Berge, The Norwegian Olympic Training Center (Olympiatoppen), Sognsveien 228, 0840 Oslo, Norway;

hilde.moseby.berge@olympiatoppen.no old recommendations, given with the best purposes, might fall.

That brings us to the editorial by Rome's Providência et al (see page 1056) who report that very few athletes who continue to compete despite cardiac disorders, experience sudden cardiac arrest. These incidents are thought the most severe in sports, and important to include in injury-and illness surveillance systems in a better way than today, as highlighted by Fortington et al (see page 1052) in their editorial. Providência and colleagues also challenge the paternalistic way that medicine decided peoples' fate. Far too many athletes might have been deprived an active life due to overcautious recommendations. Enlightened by new research showing increased survival after sports-related sudden cardiac arrest, it is easier to discuss options for a further career with the athlete patient. Shared decision making is also encouraged in the editorial by Drew et al (see page 1054). They also support that the principles of system thinking should be extended into research fields of health and coaching to integrate these parts to improve performance.

\section{THIS ISSUE: WORKING TOO HARD FOR A GOOD NIGHT'S SLEEP?}

Join us in enjoying BJSM's new regular feature, Inside Track-designed to share the values and habits of highly effective leaders in sport and exercise medicine and physiotherapy. Of the 10 banked profiles (see 'Current articles online first') we chose Norway's sports medicine leader, professor Roald Bahr, who has contributed for more than 17 years as a cofounder and cochair of the renowned Oslo Sports Trauma Research Center (OSTRC). You can learn from him here (see page 1099) and we applaud his contribution with great trainees to the following papers:

- Haugsboe Andersson et al (see page 1073) share an effective way to prevent overuse shoulder injuries among throwing athletes;

- A handy infographic provides guidance to prevent illness in athletes (see page 1093);

- Arnhild Bakken et al (see page 1081) argue that functional movements tests cannot be recommended as a screening battery, due to inter-season, intraindividual and intra-rater variability; and finally;

- Arnlaug Wangensteen et al (see page 1087) answer the question posed by many clinicians who work with elite players in professional sports-when is the best time to obtain a magnetic resonance imaging (MRI) scan following an acute (hamstring) muscle injury.

Sticking with MRI, we know it is the best imaging technique for rib stress fractures in elite rowers, but the Education Review indicates that ultrasound is a promising alternative (see page 1093). All that is promising in sports medicine is sweet music for professor Bahr, and that is why his best advice for upcoming sports medicine professionals is to find the nearest ultrasound machine and learn how to use it. If we can reply with advice for him, it would be to check out the Twilight app for healthy sleep (see page 1103). It would be interesting to know if avoiding the bluelight exposure might improve sleep quality so he can enjoy breakfast with his family. We wish you the best of summer from Norway and alert our international friends to the Scandinavian Congress in Science and Medicine in Sport-February 2018 in Copenhagen.

Competing interests None declared.

Provenance and peer review Commissioned; internally peer reviewed.

(C) Article author(s) (or their employer(s) unless otherwise stated in the text of the article) 2017. All rights reserved. No commercial use is permitted unless otherwise expressly granted.

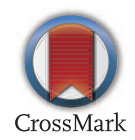

To cite Berge HM. Br J Sports Med 2017;51:1047.

Br J Sports Med 2017;51:1047. doi:10.1136/bjsports-2017-098062 